\title{
Dietary Habits of adolescents in higher secondary school in Bhutan: An In-Depth Analysis of Nationally Representative Data
}

\author{
Dorji Penjor, Tashi Phuntsho, Kinley Wangchuk, Daw Tshering, Sangay Wangchuk
}

\author{
Department of Science and Math, Samtse College of Education, Royal University of Bhutan, Bhutan \\ Received: 26 Jul 2021; Received in revised form: 25 Aug 2021; Accepted: 03 Sep 2021 \\ (C)2021 The Author(s). Published by TheShillonga. This is an open access article under the CC BY license \\ (https://creativecommons.org/licenses/by/4.0/)
}

\begin{abstract}
Bhutan is a small landlocked country that lies between the two most populous countries in the world India and China, with a total area of 38,394 square kilometers. A peaceful mountainous kingdom in the Himalayas mandated free education to all children of school-going age up to the $12^{\text {th }}$ standard. Recognizing that education is the fundamental link to national progress, the Royal Government of Bhutan has always and will continue to emphasize education as a priority sector, In doing so, through a dynamic professional health system in the country, Bhutan has made enormous strides in the field of education that promote healthy and happy school children. However, as Bhutan steadily proceeds along its development path, substantial challenges remain, including the dietary habits of an adolescent in higher secondary schools. Therefore, this paper intends to explore the dietary habits among adolescents in higher secondary school. And this will contribute empirical data evidence for the policy framers and implements of the nutrition department at higher authority and school level to improve the dietary habits of adolescents.
\end{abstract}

Keywords-Dietary Habits, Adolescents, Nutrition, Educations, and Bhutan

\section{INTRODUCTION}

Bhutan's education journey started with monastic education until 1955 when modern education was first introduced during the reign of His Majesty King Jigme Dorji Wangchuck (Schuelka 2012). Monastic education continues even today and now there is an extensive network of schools and institutes spread across the country. The constitution of Bhutan (RGoB, 2007) guarantees in Articles 9.16 that education as one of the fundamental rights to all individuals. It stated, "The State shall provide free education to all children of schoolgoing age up to the tenth standard and ensure that technical and professional education shall be made generally available and that higher education shall be equally accessible to all based on merit". Therefore, school-based education in Bhutan offered all citizens 11 years of free basic education. However, the current ruling government, of Druk Nyamrup Tshogpa has extended the basic minimum education from class $\mathrm{X}$ to XII, which is 13 years (MoE, 2020).
Education remains a priority for Royal Government of Bhutan, which is committed to providing free and high quality basic education for all. However, among all the factors influencing the learning process of adolescents in higher secondary schools, the highest priority has been given to the dietary programs for the students. The World Food Programme ([WFP], 2019) supported the fact that School meals have a significant impact on the quality and access of children to education. School feeding and nutrition programs in Bhutan focus on enhancing the schools' ability to provide balanced, nutritious, safe, sufficient, and prepared in a clean and hygienic environment using fresh local foods from the school gardens and the communities.

For this reason, the Royal Government of Bhutan, in recognition of the utmost importance of the dietary habits of adolescents in school, has initiated and implemented various national policies and programs for their health and well-being. Some of these include the implementation of the National multi-sectoral youth policy; the 
Comprehensive School and Adolescent Health Programs; and inclusion of adolescent health in various national policies and programs in different sectors.

\section{PROBLEM STATEMENT}

The first national nutrition survey was conducted in 198688 , which included only a few schools in the country. Henceforth, other studies were conducted consecutively in 1989 and 2008. In order to close the urgently needed data gap on health behaviors among adolescents in Bhutan, the RGoB successfully conducted its first Global School-based Student Health Survey (GSHS) in 2016, which aims to generate nationally representative data on various health risk behaviors, such as dietary habits, hygienic behavior, interpersonal violence, mental health, substance abuse (including tobacco, alcohol, and drug use), sexual practices and awareness of HIV/ AIDS, and also assessed protective factors among secondary school students of the age of 1317 year. A total of 50 out of 522 schools, and 7990 out of 169,560 students were sampled for studies. There is a lack of yearly national data on health behaviors and protective factors in adolescents in order to effectively and strategically guide policymakers and stakeholders to further promote the health and wellbeing of adolescents in higher secondary schools in Bhutan. The previous studies focused on a few specific schools and yet there was no data to show the approach across the country. The previous data analysis also reveals the vague findings, which will make it difficult for readers to understand the links between the studies.

\section{LITERATURE REVIEW}

\section{Adolescent in Bhutan}

Adolescence is perhaps the most controversial phase of human development. Since the beginning of this century, dozens of theories have been proposed to explain this stage of growth, each claiming to be based on attentive observation and systematic investigation. Many theories described adolescence as a stage of life when physical, psychological, and emotional changes occur (Pam, 2018). This quick biological and psychological changes during these period offer ascent to new wellbeing needs and risks, subsequently making this age group particularly vulnerable all over the world. According to Dorji (2015) among many challenges, the sizable group of young people faces unique emotional and physical health challenges while they represent the important group of people to shoulder the future responsibilities. The committed government under the guidance of successive Kings has extended a remarkable range of health services in the country, resulting in significant improvements in living conditions.
Between 2005 and 2017, the crude death rate has seen a slight reduction from 7.1 to 6.7 and the life expectancy has more than doubled to 70.2 years in 2017, from 32.4 years in 1960 (Ministry of Health $[\mathrm{MoH}], 2020$ ). However, as Bhutan steadily proceeds along its development path, substantial challenges remain, including dietary habits in an adolescent at higher secondary schools. Therefore, this paper intends to explore the dietary habits among adolescents in higher secondary school. And this will contribute empirical data evidence for the policy framers and implementers of the nutrition department at higher authority and school level to improve the dietary habits of our adolescents.

Adolescents (10-18 years of age) are a basic progress period in a human being's life, for what it's worth during this time is that the establishments for health and prosperity are set up (World Health Organization [WHO], 2020). The Department of Youth and Sports ([DYS] 2011) considers an adolescent as a person in the age range of 1324 years and the United Nations Population Fund ([UNFPA] 2019) defines an adolescent as a person in the age range 10-19 years. The health status of older age is generally a result of the health practices started at a young age. A few conduct risk factors, like unhealthy dietary practices, lack of physical fitness activities, poor hygiene, and substance abuse among our students require exceptional consideration. From those large numbers of risk factors, the dietary habits among adolescents in higher secondary schools catch the unavoidable intervention to be implemented. As unhealthy practices rooted from adolescent age will lead to non-communicable diseases in adulthood, finally, add to early death. The control of these risk factors later in life turns out to be incredibly troublesome because, after some time, they become a basic piece of an individual's way of life.

\section{Concern on the Adolescent and Dietary Habits in Bhutan}

The World Health Organization (WHO) estimates that around 1.2 billion in the world today, making up $16 \%$ of the world's population, are adolescents (WHO, 2020). According to Dorji (2015) Adolescents constitute more than half of Bhutan's population, and the $10-24$ year old population comprises about $56 \%$ of the total population. School enrolment exceeds $98 \%$ - only $1.2 \%$ of primaryage children are estimated to be out of school (Dorji, 2015). WHO (2018) noted that non-communicable diseases, including diabetes and obesity, are a major challenge for health and development, particularly in developing countries, where $85 \%$ of premature deaths occur. Subsequently, the essential prevention of risk factors among adolescents in higher secondary school is of critical importance. 
Recognizing the utmost importance of this group of the population, the Ministry of Education(MoE), Ministry of Health $(\mathrm{MoH})$, and Ministry of Agriculture and Forestry (MoAF) has initiated and has been implementing various national policies and programs for the good dietary habits practices. Some of these include the implementation of the National multi-sectoral youth policy; the Comprehensive School and Adolescent Health Programs and developed School Feeding Strategy for inclusion adolescents. To effectively and strategically guide policymakers and stakeholders to further promote the health and wellbeing of adolescents in higher secondary school students, the comprehensive national studies on dietary habits have to be on a continuous track. Therefore, to address the muchneeded data gap on health behaviors among adolescents in Bhutan, The Royal Government of Bhutan (RGoB) had conducted the National Nutrition Survey in different consecutive years.

\section{METHODOLOGY}

We used theoretical descriptive analysis to compare statistical records of the health of adolescents' health in the Bhutanese education system. For this analysis, we used the 2016 National Nutrition Survey (NNS) report as the primary data source for this study. In addition, we used NNS 1986-1988 (first; Directorate of Health Services, 1989), NNS 1999 (second; Namgyal \& Yoezer, 1999), NNS 2008 (third), and the Multiple Indicator Cluster Survey (MICS) 2010 to provide comparative information on the time trends of child malnutrition in the country.

\section{RESULTS}

According to the first national nutrition survey of 1986-88, the nutritional status of children (0-6 years) had grave concern, as both the prevalence of underweight (34.0\%) and the prevalence of stunting $(60.9 \%)$ are considered to be serious public health problems according to the World Health Organization (Directorate of Health Services, 1989). The results of a survey in 1996 in one Central and two Eastern districts present the nutritional status of children under 5 years similar to the 1986-88 results (MoE, 1999: Aguayo, et.al., 2014). According to Wangmo et.al. (2012) and MoE (2008), the occurrence of stunting for preschool children fell from $60.9 \%$ in $1986-88$ to $34.9 \%$ in 2008, and underweight declined from $34.0 \%$ to $10.4 \%$ during the same period. Aguayo, et.al. (2018) reported an average decline in stunting in preschool-aged children was $1.3 \%$ per year between $1986 / 1988$ to 2008 . The above national nutrition survey was conducted only in some regions in the country for certain age groups and the lack of data in Bhutan makes a comprehensive overview of the dietary habits in adolescents difficult. The Only nationwide nutrition survey on the dietary habits among higher secondary students was conducted by the Global School-Based Student Health Survey (GSHS) in 2016 with a sample of 50 schools and 7990 students. GSHS (2016) reported that the prevalence of under nutrition from the 2015 National Nutrition Survey is at 21 percent for stunting, 4 percent for wasting, and 9 percent for underweight. The report primarily focused on the dietary habits among students (10-18 years of age) and found out that about $40 \%$ of the students reported drinking carbonated soft drinks one or more times a day. In addition, only $32.1 \%$ reported that eating fruits two or more times a day and $42 \%$ of eating vegetables three or more times a day. About $32.2 \%$ of the students reported eating fast food for 4 or more days during the 7 days preceding the survey. This data shows that the healthy dietary trait among the adolescent in higher secondary is still in a long way for the improvement.

\section{DISCUSSION AND RECOMMENDATIONS}

WHO (2020) emphasized that consuming a healthy diet throughout the life course helps to prevent malnutrition as well as a range of non-communicable diseases (NCDs). However, increased production of processed foods, rapid urbanization, and changing lifestyles have led to a shift in dietary patterns.World Food Programme ([WFP] 2019) reported that the traditional Bhutanese diet is high in consumption of carbohydrates and animal fats, with low level of consumption of fruits and vegetables, as $67 \%$ do not consume adequate fruits or vegetables. Salt consumption is also high at 9 grams a day, almost double the WHO recommended level of $5 \mathrm{~g} /$ day. Therefore, to address the much-needed guidance on healthy dietary habits among adolescents in higher secondary school, the Ministry of Education incorporated with others ministries had come up with strategies to improve the dietary habits through nutritious school meals.

School Feeding Program (SFP) was started in 1974 jointly between the Royal Government of Bhutan and the World Food Programme (WFP) after the arrival of the latter's assistance in the country (Nutrition Activities in Bhutan 2019-2023, 2019). According to MoE (2019), during the academic year 2018, there were total of 166, 989 students, of which 88, 320 from 263 school students, were covered under the school feeding program. Of which 40, 664 were in boarding schools with 3 meals served, while 33, 531 students were provided 2 meals under WFP support, and 14, 413 students received one meal in a day school program. The first intervention to improve dietary habit was the increased in the Stipend. According to MoAF (2019), for boarding school students who receive 3 meals a 
day is was increased to $\mathrm{Nu} .1500$ per child per month, 1,000 for students receiving two meals, and $\mathrm{Nu} .500$ for day scholars receiving a midday meal. In the second strategy, MoAF (2019) encouraged the districts to implement a program to link farm and schools.WFP supported the renewal of the annual contracts for the supply of fresh local vegetables to the schools. This has been suggested to reduce Pesticide/chemical residues in imported poor quality fruits and vegetables, to prevent the major cause of morbidity, mortality, and poor classroom performance. WFP supported the Ministry of Education in this transition by developing cost-optimized nutritious school menus based on local and seasonal foods using an online menu optimizer platform. WFP also provided Fortified rice, which helps in meets multiple micronutrient requirements of school children (WFP, 2019: WFP 2021). Finally, the School's health and nutrition division under the Ministry of Health reviewed the school's food menu and incorporated the changes. The students were served fruits, dairy products, meats, eggs, and chickpea weekly to meet the balanced diet. Another visible changes in school meals was serving of vegetable soup instead of morning tea with fried rice.

Still, in the school system, the intake of meals was dominated by the source of carbohydrates where health sectors warned, taking too many carbohydrates can contribute to health problems, from the short-term discomfort to long-term chronic disease. $99 \%$ in boarding schools were served fried rice every morning. WHO (2020) warned that overconsumption of fried rice may cause heart-related disease in the long term. Although school observed every Thursday as a junk food-free day, Education Monitory Division (2018) reported that there was no sign of declination in the consumption of junk foods among high schools students. Education and health are interconnected, poor health will affect learning and poor educational outcomes will affect health, therefore the essential prevention of risk factors among adolescents in higher secondary school is of critical importance.

\section{CONCLUSION}

Education remains a priority of the Royal Government of Bhutan, which advocates free, quality education for all and expanding the School Feeding and Nutrition Programme (NSFNP) to support the most vulnerable groups of students. However, Bhutanese school-going adolescents still require focused interventions to reduce risk factors for non-communicable diseases (NCDs). This literature is designed to convey the upstream policymakers and the downstream programmatic level to closely monitor and implement the holistic policies adopted to intervene early, since these behaviors may extend into adult life, fuelling the NCD epidemic in the country. In the future, this paper will help mess Coordinators and principals in school on improving the diet through the integration of knowledge and skills of health, agriculture, nutrition and WASH in liaison with other agencies like Bhutan Agriculture Food and Regulatory Authority (BAFRA), Ministry of Health, Food Corporation of Bhutan Limited (FCBL) and other relevant agencies.

\section{ACKNOWLEDGEMENTS}

First of all, we would like to thank our sincere gratitude to the Teacher Professional and Support Division (TPSD) and the Samtse College of Education for awarding the Master scholarship programme for us. In addition, we would like to thank Mr. Sangay Tshering for the thoughtful comments and recommendations of this review. We would also like to thank the Ministry of Education, especially Sir Dezang Dorji (Nutrition Department) and Mr. Choki Dorji (Mess coordinators of Taktse Central School) for providing relevant data and information.Finally, we would like to thank all of our tutors for their unconditional supports in developing our academic carreers.

\section{REFERENCES}

[1] Aguayo,V.M.,Badgaiyan,N.,\&Paintal,K.(2014). Determinants of child stunting in the Royal Kingdom of Bhutan: an in-depth analysis of nationally representative data. Maternal \& Child Nutrition. 11,333-345. DOI: $10.1111 / \mathrm{mcn} .12168$.

[2] Bhutan Global School-Based Student Health Survey (2016). Ministry of Health, Royal Government of Bhutan and World Health Organization. 9789290226208-eng.pdf (who.int).

[3] Department of Youth and Sports (2011). The National Youth Policy. Ministry of education, Royal Government of Bhutan. Bhutan_2011_National_Youth_Policy.pdf (youthpolicy.org)

[4] Directorate of Health Services (1989). Report on the national nutrition survey. Ministry of Health, Government of Bhutan. Nutrition country profiles: Bhutan summary (fao.org).

[5] Dorji,L. (2015). Sexual and Reproductive Health of Adolescents and Youth in Bhutan, National Statistics Bureau. National Statistics Bureau (nsb.gov.bt).

[6] Kang,Y.,Aguayo,V.M.,Campbell,R.K.,Dzed,L.,Joshi,V.,W aid,J.L.,Gupta,S.D.,Haselow,N.J.\&West,K.P.(2018).

Nutritional status and risk factors for stunting in preschool children in Bhutan.;14 (S4):https://doi.org/10.1111/mcn.12653.

[7] Ministry of Agriculture \& Forests (2019). White Paper on Bhutan School \& Hospital Feeding Program. Download | Ministry of Agriculture and Forests (moaf.gov.bt). 
[8] Ministry of Education (2018).The National Education Policy.

[9] Ministry of Education (2019) School Feeding and Nutrition and Feeding Strategy 2019-2030.

[10] Ministry of Education. (2020). Bhutan Professional Standard for Teacher (BPST). Thimphu: Teacher professional support division, Bhutan.

[11] Ministry of Health (2020). Annual Health Bulletin. Microsoft Word - Bulletin_2020_Final(1)19-5-2020 (moh.gov.bt).

[12] Ministry of Health and Ministry of Education (2007). Comprehensive School HealthProgramme. COMPREHENSIVE SCHOOL HEALTH PROMOTION (education.gov.bt).

[13] Ministry of Health (2008). National Nutrition, Infant and Young Child Feeding Survey, 2008.Thimphu, Bhutan. Bhutan National Nutrition, Infant and Young Child Feeding Survey 2008 GHDx (healthdata.org).

[14] Ministry of Health (2008). National Nutrition, Infant and Young Child Feeding Survey, 2008.Thimphu, Bhutan. Bhutan National Nutrition, Infant and Young Child Feeding Survey 2008 GHDx (healthdata.org).

[15] Pam M.S., (2018). Adolescent theories. What is ADOLESCENCE (Theories)? definition of ADOLESCENCE (Theories) (Psychology Dictionary)

[16] Royal Government of Bhutan. (2007). The constitution of the kingdom of Bhutan. Thimphu: Royal Government of Bhutan.

[17] Schuelka, M. J. (2012). "Inclusive Education in Bhutan: A Small State with Alternative Priorities." Current Issues in Comparative Education 15 (1): 145-156.

[18] United Nations Population Fund (2019). Adolescent and Youth Sexual and Reproductive Health and Rights Services. EN-UNFPA-WCARO-MUSKOKA-ECSAYSRHR-ReportWEB.pdf

[19] World Food Programme (2019). Overview of Nutrition Activities in Bhutan 2019-2023. Overview of Nutrition Activities in Bhutan 2019-2023 | World Food Programme (wfp.org).

[20] World food programme (2021). WFP Bhutan Country Brief https://docs.wfp.org/api/documents/WFP0000122984/download/.

[21] World Health Organization (2018). Non- communicable diseases. Noncommunicable diseases (who.int).

[22] World Health Organization (2020). Adolescent health. Adolescent and young adult health (who.int).

[23] World Health Organization (2020). Healthy diet. Healthy diet (who.int).

[24] Zangmo, U., de Onis, M., \& Dorji, T. (2012). The nutritional status of children in Bhutan:Results from the 2008 national nutrition survey and trends over time. BMC Pediatrics, 12. 